\title{
Article
}

\section{Effects of barefoot and shod running on lower extremity joint loading, a musculoskeletal simulation study}

Sinclair, Jonathan Kenneth

Available at http://clok.uclan.ac.uk/21974/

Sinclair, Jonathan Kenneth ORCID: 0000-0002-2231-3732 (2018) Effects of barefoot and shod running on lower extremity joint loading, a musculoskeletal simulation study. Sport Sciences for Health . ISSN 1824-7490

It is advisable to refer to the publisher's version if you intend to cite from the work. http://dx.doi.org/10.1007/s11332-018-0446-1

For more information about UCLan's research in this area go to http://www.uclan.ac.uk/researchgroups/ and search for <name of research Group>.

For information about Research generally at UCLan please go to http://www.uclan.ac.uk/research/

All outputs in CLoK are protected by Intellectual Property Rights law, including Copyright law. Copyright, IPR and Moral Rights for the works on this site are retained by the individual authors and/or other copyright owners. Terms and conditions for use of this material are defined in the policies page.

\section{CLoK}

Central Lancashire online Knowledge www.clok.uclan.ac.uk

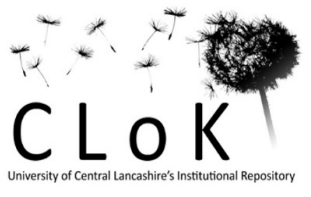




\section{Correspondence Address:}

7 Dr. Jonathan Sinclair

8 Centre for Applied Sport \& Exercise Sciences

$9 \quad$ Faculty of Health and Wellbeing

10 University of Central Lancashire

11 Preston

12 Lancashire

13 PR1 2HE.

14 e-mail: jksinclair@uclan.ac.uk

15 Keywords: Biomechanics; barefoot; musculoskeletal; joint

\section{Abstract}

17 PURPOSE: The aim of the current investigation was to utilize a musculoskeletal simulation based approach, to examine the effects of barefoot and shod running on lower extremity joint

19 loading during the stance phase. 
METHODS: Twelve male runners, ran over an embedded force plate at $4.0 \mathrm{~m} / \mathrm{s}$, in both barefoot and shod conditions. Kinematics of the lower extremities were collected using an eight camera motion capture system. Lower extremity joint loading was also explored using a musculoskeletal simulation and mathematical modelling approach, and differences between footwear conditions were examined using paired samples t-tests.

RESULTS: Peak Achilles tendon force was significantly larger $(\mathrm{P}=0.039)$ when running barefoot $(6.85 \mathrm{BW})$ compared to shod $(6.07 \mathrm{BW})$. In addition, both medial $(\mathrm{P}=0.013)$ and lateral $(\mathrm{P}=0.007)$ tibiofemoral instantaneous load rates were significantly larger in the barefoot $($ medial $=289.17 \mathrm{BW} / \mathrm{s} \&$ lateral $=179.59 \mathrm{BW} / \mathrm{s})$ in relation to the shod $($ medial $=$ 167.57 BW/s \& lateral $=116.40 \mathrm{BW} / \mathrm{s})$ condition. Finally, the barefoot condition $(9.70 \mathrm{BW})$ was associated with a significantly larger $(\mathrm{P}=0.037)$ peak hip force compared to running shod (8.51 BW).

CONCLUSIONS: The current investigation indicates that running barefoot may place runners at increased risk from the biomechanical factors linked to the aetiology of chronic lower extremity pathologies. However, future analyses using habitual barefoot runners, are required before more definitive affirmations regarding injury predisposition can be made.

\section{Introduction}

Running is an extremely popular exercise modality. It has been projected that as many as 2 million people in the UK utilize running as a mode of exercise (1). There is an overwhelming body of evidence, which has emphasized the physiological and psychological benefits of physical activity and exercise (2). However, despite the plethora of physical benefits 
42 associated with regular running, it is also associated with a high incidence of chronic

43 pathologies. Each year, up to $80 \%$ of runners will suffer an overuse injury (3).

The knee joint is most susceptible to chronic pathology in runners (3). Specifically,

patellofemoral pain syndrome is the most frequent overuse injury encountered in runners (4),

characterized by pain at or anterior to the patella aggravated by physical activities that load

the patellofemoral joint (5). Pain symptoms are related to excessive patellofemoral loading

and typically persist for many years (6). A recent epidemiological analysis has shown that

there may be a link between patellofemoral pain in younger adults and subsequent

osteoarthritis at this joint (7). Furthermore, tibiofemoral pathologies are also common chronic

running injuries; associated with up to $16.8 \%$ of all knee injuries (8). The medial aspect of the

tibiofemoral joint is known to be significantly more prone to osteoarthritic degeneration than

the lateral compartment (9). The causes of tibiofemoral chronic pathologies relate to the

magnitude of the stress loading of the joint (10), which is considered to be the mechanical

parameter most strongly associated with the onset and progression of knee osteoarthritis. The

mechanism responsible for this is thought to be the increased joint contact forces experienced

by the medial compartment of the tibiofemoral joint during locomotion (11). Finally, Achilles

tendinopathies are also frequently occurring chronic musculoskeletal disorders in runners,

tendinopathy is considered to be associated with habitual and excessive mechanical loading

64 An array of different treatment/ preventative modalities, have therefore been investigated in 65 an attempt to attenuate the risk of running injuries. An extremely popular conservative 
strategy is to select running trainers with appropriate biomechanical properties, as running shoes are proposed as a mechanism by which the rate of chronic injuries can be controlled

68 (14). Recently however, it has been proposed that running using traditional running shoes may place runners at increased risk from the biomechanical factors linked to the aetiology of chronic running injuries (15). This led to a new proposal in footwear research, that running barefoot footwear may be associated with a reduced incidence of chronic running injuries (15). Based on this hypothesis, a number of runners are now choosing to run barefoot or in minimalist footwear $(16,17)$.

In recent years, barefoot running has received considerable research attention in biomechanical literature. Using a mathematical modelling approach driven by sagittal plane external joint torques and knee kinematics, both Bonacci et al., (18) and Sinclair, (19) showed that running barefoot significantly reduced patellofemoral joint loading during the stance phase of running. Furthermore, using external joint torques and ankle joint kinematics, Sinclair, (19) revealed that barefoot running was associated with significantly increased Achilles tendon forces in comparison to running shod. Finally, Sinclair et al., (16) and Sinclair et al., (17) found that barefoot running significantly increased the loading rate of the external vertical ground reaction force. Previous analyses concerning the biomechanical differences between barefoot and shod running, have utilized either the external ground reaction force or joint torque driven mathematical modelling approaches to explore the loads experienced by the musculoskeletal system. However, the external ground reaction force and joint torques represent global indices of joint loading, and therefore are not representative of localized joint loading (20). Herzog et al., (21) showed that muscles are the primary contributors to lower extremity joint loading. Yet the complex role of muscles in controlling 
joint biomechanics during human movement has received insufficient attention within the literature, possibly due to difficulties in calculating muscle kinetics.

However, advances in musculoskeletal modelling have led to the development of bespoke software which allows skeletal muscle force distributions to be simulated during movement using motion capture based data (22). To date, such approaches have not yet been utilized to explore biomechanical differences between barefoot and shod running. Therefore, the aim of the current investigation was to examine the effects of barefoot and shod running on lower extremity joint loading using a musculoskeletal simulation based approach. A study of this nature may provide further insight into the biomechanical differences between barefoot and shod running; particularly with regards to runners' susceptibility to chronic pathologies.

\section{Methods}

\section{Participants}

Twelve healthy male runners, volunteered to take part in this study. All were identified as recreational runners who trained 3 times/week, completing a minimum of $35 \mathrm{~km}$. The participants provided written informed consent in accordance with the principles outlined in the Declaration of Helsinki. The mean characteristics of the participants were; age $24.33 \pm$ 4.09 years, height $1.77 \pm 0.09 \mathrm{~cm}$ and body mass $75.44 \pm 6.58 \mathrm{~kg}$. The procedure utilized for this investigation was approved by the University of Central Lancashire, Science, Technology, Engineering and Mathematics, ethical committee. 
113 Participants ran at $4.0 \mathrm{~m} / \mathrm{s}( \pm 5 \%)$, striking an embedded piezoelectric force platform (Kistler,

114 Kistler Instruments Ltd., Alton, Hampshire) with their right foot. Running velocity was 115 monitored using infrared timing gates (Newtest, Oy Koulukatu, Finland). The stance phase 116 was delineated as the duration over which $20 \mathrm{~N}$ or greater of vertical force was applied to the 117 force platform (23). Runners completed a minimum of five successful trials in both barefoot and shod conditions. The shod condition (New Balance $1260 \mathrm{v} 2$ ) had an average mass of $0.285 \mathrm{~kg}$, heel thickness of $25 \mathrm{~mm}$ and a heel drop of $14 \mathrm{~mm}$. The order that participants ran in each footwear condition was counterbalanced. Kinematics and ground reaction forces data were synchronously collected. Kinematic data was captured at $250 \mathrm{~Hz}$ via an eight camera motion analysis system (Qualisys Medical AB, Goteburg, Sweden). Dynamic calibration of the motion capture system was performed before each data collection session.

To define the anatomical frames of the thorax, pelvis, thighs, shanks and feet retroreflective markers were placed at the $\mathrm{C} 7, \mathrm{~T} 12$ and xiphoid process landmarks and also positioned bilaterally onto the acromion process, iliac crest, anterior superior iliac spine (ASIS), posterior super iliac spine (PSIS), medial and lateral malleoli, medial and lateral femoral epicondyles, greater trochanter, calcaneus, first metatarsal and fifth metatarsal. Carbon-fibre tracking clusters comprising of four non-linear retroreflective markers were positioned onto the thigh and shank segments. In addition to these the foot segments were tracked via the calcaneus, first metatarsal and fifth metatarsal, the pelvic segment was tracked using the PSIS and ASIS markers and the thorax segment was tracked using the T12, C7 and xiphoid markers. The shod condition was modified by cutting windows into the experimental 

obtained with the participant in the anatomical position in order for the positions of the anatomical markers to be referenced in relation to the tracking clusters/markers. A static trial was conducted with the participant in the anatomical position in order for the anatomical positions to be referenced in relation to the tracking markers, following which those not required for dynamic data were removed.

\section{Processing}

Dynamic trials were digitized using Qualisys Track Manager in order to identify anatomical and tracking markers then exported as C3D files to Visual 3D (C-Motion, Germantown, MD, USA). All data were normalized to $100 \%$ of the stance phase. Ground reaction force and kinematic data were smoothed using cut-off frequencies of 50 and $12 \mathrm{~Hz}$ with a low-pass Butterworth 4th order zero lag filter (26). All net joint force parameters throughout were normalized by dividing by bodyweight (BW). Kinematic measures from the hip, knee, ankle which were extracted for statistical analysis were 1) angle at footstrike, 2) peak flexion/ dorsiflexion during the stance phase and 3) angular range of motion (ROM) from footstrike to peak angle.

Data during the stance phase were exported from Visual 3D into OpenSim 3.3 software (Simtk.org). A validated musculoskeletal model with 12 segments, 19 degrees of freedom and 92 musculotendon actuators (27) was used to estimate extremity joint forces. The model was scaled for each participant to account for the anthropometrics of each athlete. As muscle 
forces are the main determinant of joint compressive forces (21), muscle kinetics were quantified using a static optimization in accordance with Steele et al., (28). Compressive medial/ lateral tibiofemoral and hip joint forces were calculated via the joint reaction analyses function using the muscle forces generated from the static optimization process as inputs. Furthermore, medial and lateral tibiofemoral contact stresses (MPa) were quantified by dividing the tibiofemoral force by the medial and lateral contact areas estimated using the data of Kettelkamp and Jacobs, (29). From the above processing, peak medial tibiofemoral force, peak lateral tibiofemoral force, peak hip force, peak medial tibiofemoral stress and peak lateral tibiofemoral stress were extracted for statistical analyses. In addition medial/ lateral tibiofemoral and hip instantaneous load rates (BW/s) were also extracted by obtaining the peak increase in force between adjacent data points.

Patellofemoral loading during the stance phase of running was quantified using a model adapted from van Eijden et al., (30) in accordance with the protocol of Willson et al., (31). A key drawback of this model is that co-contraction of the knee flexor musculature is not accounted for. Taking this into account, summed hamstring and gastrocnemius forces derived from the static optimization procedure were multiplied by their estimated knee joint muscle moment arms as a function of knee flexion angle (32), and then added together to determine the knee flexor torque during the stance phase. In addition to this, the knee extensor torque was also calculated by dividing the summed quadriceps forces by this muscle groups' knee joint muscle moment arms as a function of knee flexion angle (30). The knee flexor and extensor torques were then summed and subsequently divided by the quadriceps muscle moment arm to obtain quadriceps force adjusted for co-contraction of the knee flexor musculature. Patellofemoral force was quantified by multiplying the derived quadriceps force by a constant which was obtained by using the data of Eijden et al., (30). Finally, 
patellofemoral joint stress $(\mathrm{MPa})$ was quantified by dividing the patellofemoral force by the patellofemoral contact area. Patellofemoral contact areas were obtained by fitting a polynomial curve to the sex specific data of Besier et al., (33), who estimated patellofemoral contact areas as a function of the knee flexion angle using MRI. From the above processing, peak patellofemoral force and peak patellofemoral stress were extracted for statistical analyses. In addition, patellofemoral instantaneous load rate (BW/s) was also extracted by obtaining the peak increase in force between adjacent data points.

Finally, Achilles tendon forces were estimated in accordance with the protocol of Almonroeder et al., (34), by summing the muscle forces of the medial gastrocnemius, lateral, gastrocnemius, and soleus muscles. From the above processing, peak Achilles tendon force and Achilles tendon instantaneous load rate (BW/s) were extracted for statistical analyses.

Running barefoot has been shown to alter the step length/ stance time during running (35), which may affect the number of footfalls required to complete a set distance. We therefore firstly calculated integral of the hip, tibiofemoral, patellofemoral and Achilles tendon forces during the stance phase, using a trapezoidal function. In addition to this, we also estimated the total force per mile (BW) by multiplying these parameters by the number of steps required to run a mile. The number of steps required to complete one mile was quantified using the step length $(\mathrm{m})$, which was determined by taking the difference in the horizontal position of the foot centre of mass between the right and left legs at footstrike. 
Means, standard deviations (SD) and $95 \%$ confidence intervals $(95 \% C I)$ were calculated for

208

209

210

211

212

213

214

215

216

217

218

219

220

221

222 each outcome measure for both footwear conditions. The data was screened for normality using Shapiro-Wilk tests which confirmed that the normality assumption was met. Differences between footwear conditions were examined using paired samples t-tests, and effect sizes were calculated using partial eta ${ }^{2}\left(\mathrm{p \eta}^{2}\right)$. Statistical actions were conducted using SPSS v23.0 (SPSS, USA).

\section{Results}

\section{Joint kinematics}

The hip was significantly $\left(\mathrm{P}=0.017, \mathrm{p \eta}^{2}=0.42\right)$ more flexed at footstrike in the shod condition. In addition, peak hip flexion was significantly $\left(\mathrm{P}=0.018, \mathrm{p} \eta^{2}=0.41\right)$ greater in the shod condition.

The ankle was significantly $\left(\mathrm{P}=0.001, \mathrm{p \eta}^{2}=0.66\right)$ more dorsiflexed at footstrike in the shod condition. In addition, peak dorsiflexion was significantly $\left(P=0.0004, \mathrm{p}^{2}=0.69\right)$ larger in the shod condition, and ankle ROM was significantly $\left(\mathrm{P}=0.032, \mathrm{p}^{2}=0.35\right)$ greater in the barefoot condition.

@@@TABLE 1 NEAR HERE @ @ @ @ @ @ FIGURE 1 NEAR HERE @ @ @ 
231 Step length was significantly $\left(\mathrm{P}=0.001, \mathrm{p} \eta^{2}=0.65\right)$ greater during shod running (Table 2$)$. In 232 addition, the number of steps per mile was significantly $\left(\mathrm{P}=0.001, \mathrm{p} \eta^{2}=0.65\right)$ lower in the 233 shod condition (Table 2).

Medial tibiofemoral force instantaneous load rate was significantly larger $\left(\mathrm{P}=0.013, \mathrm{p} \eta^{2}=\right.$ 237 0.33) in the barefoot condition (Table 3). In addition, lateral tibiofemoral force instantaneous load rate was significantly larger $\left(\mathrm{P}=0.007, \mathrm{p}^{2}=0.50\right)$ in the barefoot condition (Table 3$)$.

Hip kinetics

241 Peak hip force was significantly larger $\left(\mathrm{P}=0.037, \mathrm{p \eta}^{2}=0.34\right)$ in the barefoot condition (Table

2423 ; Figure 3e). In addition, hip instantaneous load rate was significantly larger $\left(\mathrm{P}=0.002, \mathrm{p} \eta^{2}=\right.$ 2430.59 ) in the barefoot condition (Table 3).

Patellofemoral kinetics

246 No differences $(\mathrm{P}>0.05)$ in patellofemoral loading were observed (Table 3-4; Figure 2ab). 
249 Peak Achilles tendon force was significantly larger $\left(\mathrm{P}=0.039, \mathrm{p} \eta^{2}=0.33\right)$ in the barefoot

250

251

252

253

254

255

256

257

258

259

260

261

262

263

264

265

266

267

268

269

.
condition (Table 3; Figure 2c). In addition, Achilles tendon force per mile was significantly larger $\left(\mathrm{P}=0.028, \mathrm{p}^{2}=0.37\right)$ in the barefoot condition (Table 4$)$.

@@@TABLE3 NEAR HERE@@@

@@@TABLE4 NEAR HERE@@@

@@@ FIGURE 2 NEAR HERE @ @ @

@@@ FIGURE 3 NEAR HERE @@@

\section{Discussion}

The aim of the current examination, was to examine the effects of barefoot and shod running on lower extremity joint loading using a musculoskeletal simulation approach. To the authors knowledge, this represents the first investigation to explore the biomechanical differences between barefoot and shod running using this methodology. This investigation provides further insight into the biomechanical differences between barefoot and shod running.

A key observation from the current analysis, is that patellofemoral loading parameters were not statistically different between barefoot and shod running. This finding opposes those of Bonacci et al., (18) and Sinclair, (19) who showed significant reductions in patellofemoral loading when running barefoot. It is proposed that this observation may relate to the specific 
kinematic adjustments that runners made in the current investigation. Typically, when running barefoot the ankle is in a plantarflexed position at footstrike (15-17), and the knee ROM is significantly reduced (19), which effectively attenuates the role of the knee as a shock absorber (19). However, the current investigation showed no differences in knee kinematics when running barefoot, and whilst the ankle angle at footstrike was significantly altered in the barefoot condition, it was still in a dorsiflexed position. As such, it appears that the kinematic adaptations that runners typically make in the absence of footwear were less pronounced in this investigation, which may consequently explain the lack of differences in patellofemoral loading. Additionally, this may relate to the manner in which patellofemoral loading was calculated in the current study, as previous analyses have used mathematical models which do not account for co-contraction of the knee flexors $(18,19)$. Nonetheless, the current investigation indicates that running barefoot may not always attenuate the patellofemoral loading parameters linked to the aetiology of patellofemoral pain in runners.

The current investigation also revealed that the rate at which both the medial and lateral aspects of the tibiofemoral joint were loaded, was significantly larger in the barefoot condition. This finding is supported by those of Sinclair et al., (36) who found that the tibiofemoral rate of loading measured using an inverse dynamics based approach was significantly larger when running barefoot, in relation to traditional running trainers. This finding may be important, as increased compressive loading at the tibiofemoral joint, is a risk factor for the onset and progression of osteoarthritis (37). Therefore, the current analysis indicates that running barefoot may increase susceptibility to the risk factors associated with tibiofemoral osteoarthritis. 
294 A further important observation from the current investigation was that Achilles tendon loading parameters were shown to be significantly larger in the barefoot condition. This observation concurs with those of Sinclair, (19), who similarly showed that Achilles tendon loading was greater when running barefoot. This observation may provide important clinical information in regards to the initiation and progression of Achilles tendinopathy (38). The aetiology of Achilles tendinopathy is mediated through repeated and excessive mechanical loading of the tendon during activities such as running. Repetitive tendon loads such as those initiate collagen and extracellular matrix synthesis and tissue degradation (39). Therefore, the current investigation shows that running barefoot may place runners at increased risk from the biomechanical parameters linked to Achilles tendinopathy.

In addition, this investigation also showed that peak compressive hip joint loading was significantly larger when running barefoot, in comparison to the shod condition. This study represents the first investigation to contrast hip joint loading during barefoot and shod running using musculoskeletal simulation, therefore comparisons against previous analyses are difficult. However, our findings are partially supported by those of Rooney \& Derrick, (40) who showed that non-rearfoot strike runners experienced significantly greater compressive hip joint loading during running. However, in their prospective investigation of running injuries in barefoot and shod runners Altman \& Davis, (41) found that hip injuries were statistically more frequent in shod runners. This appears to be contradictory as hip joint pathologies are strongly influenced by compressive hip joint loading (42). It is clear from this observation that further epidemiological research is required concerning the potential clinical influence of running barefoot. 
318 A potential drawback to the current study is that it examined only habitual shod runners, who

319 do not customarily run barefoot. Previous work examining the biomechanics of running

320 barefoot has drawn conflicting observations, often on the basis of the barefoot running

321 experience of their participants $(15-17,43)$. It can therefore, be speculated that the results

322 from the current analysis may have been different had a sample of habitual barefoot runners

323 been examined. Therefore, repeating the current investigation using habitual barefoot runners

324 is advisable for future research, which may allow more definitive assertions with regards to

325 injury predisposition to be made. That this study utilized a simulation based procedure to

quantify muscles forces and joint loading may also serve as a limitation. Whist this procedure

is considered an improvement over previous approaches, in that joint reaction analyses are

representative of localized joint loading and muscular co-contraction is accounted for.

Musculoskeletal simulations depend on the underlying mathematical model and numerous

mechanical assumptions are made in the construction of musculoskeletal simulation models

(22). These predominately relate to the constrained rotational degrees of freedom at the knee

and ankle joints and the lack of key muscles such as recuts abdominis, which may lead to

incorrectly predicted muscle forces. However, as direct quantification of muscle forces are

not possible at this time, the current procedure is the most practicable method in dynamic

In conclusion, although the biomechanics of barefoot running have received extensive research attention; there has yet to be a quantitative comparison of lower extremity joint loading during barefoot and shod running using a musculoskeletal simulation based approach. comprehensive evaluation of lower extremity joint loading during barefoot and shod running conditions. On the basis that hip, tibiofemoral and Achilles tendon loading parameters were 
significantly greater when running barefoot, the findings from the current investigation 344 indicate that barefoot running may place runners at increased risk from the biomechanical 345 risk factors linked to the aetiology of chronic lower extremity pathologies. However, future 346 analyses using habitual barefoot runners, are required before more definitive affirmations 347 regarding injury predisposition can be made.

\section{Acknowledgements}

We thank Gareth Shadwell for his technical assistance.

\section{Compliance with ethical standards}

Conflict of interest

354 We declare that we have no conflict of interest.

\section{Ethical approval}

The current research project was approved by an institutional ethical panel. All procedures performed in studies involving human participants were in accordance with the ethical standards of the institutional and the declaration of Helsinki.

\section{Informed consent}

All of the subjects provided written consent.

\section{References}

1. http://www.sportengland.org/media-centre/news/2014/september/05/sport-englandjoins-the-great-north-run-team/

2. Warburton DE, Nicol CW, Bredin SS (2006). Health benefits of physical activity: the evidence. CMAJ 174: 801-809. DOI: 10.1503/cmaj.051351 
3. van Gent RN, Siem D, van Middelkoop M, van Os AG, Bierma-Zeinstra SMA, Koes

BW (2007). Incidence and determinants of lower extremity running injuries in long

distance runners: a systematic review. $\mathrm{Br} \mathrm{J}$ Sports Med 41: 469-480. DOI: 10.1136/bjsm.2006.033548

4. Crossley KM (2014). Is patellofemoral osteoarthritis a common sequela of patellofemoral pain? $\mathrm{Br}$ J Sports Med 48: 409-410. DOI: http://dx.doi.org/10.1136/bjsports-2014-093445

5. Crossley KM, Stefanik JJ, Selfe J, Collins NJ, Davis IS, Powers CM, McConnell J, Vicenzino B, Bazett-Jones BM, Esculier J-F, Morrissey D, Callaghan MJ (2016). Patellofemoral pain consensus statement from the 4th International Patellofemoral Pain Research Retreat, Manchester. Part 1: Terminology, definitions, clinical examination, natural history, patellofemoral osteoarthritis and patient-reported $\begin{array}{lllllll}\text { outcome measures. } & \mathrm{Br} & \mathrm{J} & \text { Sports } & \text { Med 50: 839-843. } & \text { DOI: }\end{array}$ http://dx.doi.org/10.1136/bjsports-2016-096384

6. Collins NJ, Bierma-Zeinstra SM, Crossley KM, van Linschoten RL, Vicenzino B, van Middelkoop M. (2012). Prognostic factors for patellofemoral pain: a multicentre observational analysis. Br J Sports Med 47: 227-233. DOI: 10.1136/bjsports-2012091696

7. Thomas MJ, Wood L, Selfe J, Peat G. (2010). Anterior knee pain in younger adults as a precursor to subsequent patellofemoral osteoarthritis: a systematic review. BMC Musculoskelet Disord, 11, 201-211. DOI: 10.1186/1471-2474-11-201.

8. Taunton JE, Ryan MB, Clement DB, McKenzie DC, Lloyd-Smith DR, Zumbo BD (2002). A retrospective case-control analysis of 2002 running injuries. Br J Sports Med 36: 95-101. DOI: http://dx.doi.org/10.1136/bjsm.36.2.95 
9. Wise BL, Niu J, Yang M, Lane NE, Harvey W, Felson DT, Lewis CE (2012). Patterns

of compartment involvement in tibiofemoral osteoarthritis in men and women and in

whites and African Americans. Arthritis Care Res 64: 847-852. DOI:

10.1002/acr.21606.

10. Morgenroth DC, Medverd JR, Seyedali M, Czerniecki JM. (2014). The relationship between knee joint loading rate during walking and degenerative changes on magnetic resonance imaging. Clin Biomech 29: 664-670. DOI: 10.1016/j.clinbiomech.2014.04.008

11. Schipplein OD, Andriacchi TP (1991). Interaction between active and passive knee stabilizers during level walking. J Orthop Res 9: 113-119.

12. Van Ginckel A, Thijs Y, Hesar NGZ, Mahieu N, De Clercq D, Roosen P, Witvrouw E. (2008). Intrinsic gait-related risk factors for Achilles tendinopathy in novice runners: a prospective study. Gait Posture 29: 387-391. DOI: 10.1016/j.gaitpost.2008.10.058

13. Cook JL, Purdam CR. (2009). Is tendon pathology a continuum? A pathology model to explain the clinical presentation of load-induced tendinopathy. Br J Sports Med 43: 409-416.DOI: http://dx.doi.org/10.1136/bjsm.2008.051193

14. Shorten, MA. Running shoe design: protection and performance. pp 159-169 in Marathon Medicine (Ed. D. Tunstall Pedoe). 2000; London, Royal Society of Medicine.

15. Lieberman DE, Venkadesan M, Werbel WA, Daoud AI, D'Andrea S, Davis IS, Mang'eni RO, Pitsiladis Y. (2010). Foot strike patterns and collision forces in habitually barefoot versus shod runners. Nature 463: 531-535. DOI:10.1038/nature08723 
16. Sinclair J, Greenhalgh A, Edmundson CJ, Brooks D, Hobbs SJ (2013). The influence of barefoot and barefoot-inspired footwear on the kinetics and kinematics of running in comparison to conventional running shoes. Footwear Sci. 5: 45-53. DOI: $10.1080 / 19424280.2012 .693543$

17. Sinclair J, Hobbs SJ, Currigan G, Taylor PJ (2013). A comparison of several barefoot inspired footwear models in relation to barefoot and conventional running footwear. Comp Ex Phys 9: 13-21. DOI: http://dx.doi.org/10.3920/CEP13004

18. Bonacci J, Vicenzino B, Spratford W, Collins P (2013). Take your shoes off to reduce patellofemoral joint stress during running. Br J Sports Med 48: 425-428. DOI: http://dx.doi.org/ 10.1136/bjsports-2013-092160

19. Sinclair J (2014). Effects of barefoot and barefoot inspired footwear on knee and ankle loading during running. Clin Biomech 29: 395-399. DOI: 10.1016/j.clinbiomech.2014.02.004

20. Herzog W, Longino D, Clark A (2003). The role of muscles in joint adaptation and degeneration. Langenbecks Arch Surg 388: 305-315. DOI:10.1007/s00423-003-04026

21. Herzog W, Clark A, Wu J. (2003). Resultant and local loading in models of joint disease. Arthritis Care Res 49: 239-247. DOI: 10.1002/art.11004

22. Delp SL, Anderson FC, Arnold AS, Loan P, Habib A, John CT, Thelen DG (2007). OpenSim: open-source software to create and analyze dynamic simulations of movement. IEEE Trans Biomed Eng 54:1940-1950. DOI: 10.1109/TBME.2007.901024

23. Sinclair J, Edmundson CJ, Brooks D, Hobbs SJ (2011). Evaluation of kinematic methods of identifying gait Events during running. International J Sp Sci Eng 5: 188192. 

kinematics of the foot with respect to the shoe using a multi-segment foot model. J Foot Ankle Res 1: 29-34. DOI: 10.1186/1757-1146-1-S1-O29

25. Sinclair J, Greenhalgh A, Taylor PJ, Edmundson CJ, Brooks D, Hobbs SJ (2013). Differences in tibiocalcaneal kinematics measured with skin-and shoe-mounted markers. Hum Mov 14: 64-69. DOI: https://doi.org/10.2478/humo-2013-0005

26. Sinclair J, Taylor PJ, Atkins S (2015). Influence of running shoes and cross-trainers on Achilles tendon forces during running compared with military boots. J R Army Med Corps 161: 140-143. DOI: 10.1136/jramc-2014-000308. Epub 2014 Nov 26.

27. Lerner ZF, DeMers MS, Delp SL, Browning RC (2015). How tibiofemoral alignment and contact locations affect predictions of medial and lateral tibiofemoral contact forces. J Biomech 48: 644-650. DOI: 10.1016/j.jbiomech.2014

28. Steele KM, DeMers MS, Schwartz MH, Delp SL (2012). Compressive tibiofemoral force during crouch gait. Gait Posture 35: 556-560. DOI: 10.1016/j.gaitpost.2011

29. Kettelkamp DB, Jacobs AW (1972). Tibiofemoral Contact Area-Determination and Implications. JBJS 54: 349-356.

30. van Eijden TM, Kouwenhoven E, Verburg J, Weijs WA (1986). A mathematical model of the patellofemoral joint. J Biomech 19: 219-229. https://doi.org/10.1016/0021-9290(86)90154-5

31. Willson JD, Ratcliff OM, Meardon SA, Willy RW (2015). Influence of step length and landing pattern on patellofemoral joint kinetics during running. Scand J Med Sci Sports 25: 736-743. DOI: 10.1111/sms.12383

32. Spoor CW, van Leeuwen JL (1992). Knee muscle moment arms from MRI and from tendon travel. J Biomech 25: 201-206. DOI: https://doi.org/10.1016/0021$\underline{9290(92) 90276-7}$ 
33. Besier TF, Draper CE, Gold GE, Beaupre GS, Delp SL. (2005). Patellofemoral joint contact area increases with knee flexion and weight-bearing. J Orthop Res 23: 345350. DOI: $10.1016 /$ j.orthres.2004.08.003

34. Almonroeder T, Willson JD, Kernozek TW. (2013). The effect of foot strike pattern on Achilles tendon load during running. Ann Biomed Eng 41: 1758-1766. DOI: 10.1007/s10439-013-0819-1.

35. Thompson M, Gutmann A, Seegmiller J, McGowan C. (2014). The effect of stride length on the dynamics of barefoot and shod running. J Biomech 47: 2745-2750. DOI: 10.1016/j.jbiomech.2014.04.043

36. Sinclair J. (2016). The Effects of Barefoot and Barefoot Inspired Footwear Running on Tibiofemoral Kinetics. Hum Mov 17: 176-180. DOI: https://doi.org/10.1515/humo-2016-0022

37. Dabiri Y, Li LP (2013). Altered knee joint mechanics in simple compression associated with early cartilage degeneration. Comput Math Methods Med 11: 1-12. DOI: http://dx.doi.org/10.1155/2013/862903

38. Selvanetti A, Cipolla M, Puddu G. (1997). Overuse tendon injuries: basic science and classification. Op Tech Sports Med 5: 110-117. DOI: https://doi.org/10.1016/S10601872(97)80031-7

39. Magnusson SP, Langberg, H, Kjaer M. (2010). The pathogenesis of tendinopathy: balancing the response to loading. Nat Rev Rheumatol 6: 262-268. DOI: 10.1038/nrrheum.2010.43

40. Rooney BD, Derrick TR (2013). Joint contact loading in forefoot and rearfoot strike patterns during running. J Biomech 46: 2201-2206. DOI: 10.1016/j.jbiomech.2013.06.022 
497 6

41. Altman AR, Davis IS (2016). Prospective comparison of running injuries between shod and barefoot runners. Br J Sports Med 50: 476-480. DOI: http://dx.doi.org/10.1136/bjsports-2014-094482

42. Johnson VL, Hunter DJ (2014). The epidemiology of osteoarthritis. Best Pract Res Clin Rheumatol 28: 5-15. DOI: 10.1016/j.berh.2014.01.004

43. Squadrone R, Gallozzi, C (2009). Biomechanical and physiological comparison of barefoot and two shod conditions in experienced barefoot runners. J Sports Med Phys Fitness 49: 6-13.

\section{Figures}

Figure 1: Joint kinematics as a function of footwear a. = hip, b. = knee and c. $=$ ankle (black $=$ barefoot and grey $=$ shod).

Figure 2: Patellofemoral and Achilles tendon kinetics as a function of footwear a. patellofemoral force, $\mathrm{b} .=$ patellofemoral stress and c. Achilles tendon force (black $=$ barefoot and grey $=$ shod).

Figure 3: Tibiofemoral and hip kinetics as a function of footwear a. = medial tibiofemoral force, b. = medial tibiofemoral stress, $\mathrm{c} .=$ lateral tibiofemoral force, d. = lateral tibiofemoral stress and e. = hip force (black = barefoot and grey $=$ shod). 
Table 1: Hip, knee and ankle kinematics (Mean, SD and 95\% CI's) as a function of footwear.

\begin{tabular}{|c|c|c|c|c|c|c|c|c|c|}
\hline & \multicolumn{4}{|c|}{ Barefoot } & \multicolumn{4}{|c|}{ Shod } & \\
\hline & Mean & $S D$ & 95\% Cl Lower & 95\% Cl Upper & Mean & $S D$ & 95\% Cl Lower & 95\% Cl Upper & \\
\hline Hip angle at footstrike $\left({ }^{\circ}\right)$ & 34.29 & 12.38 & 26.42 & 42.15 & 42.27 & 7.77 & 37.34 & 47.21 & * \\
\hline Peak hip flexion $\left({ }^{\circ}\right)$ & 34.84 & 12.03 & 27.20 & 42.49 & 42.76 & 7.24 & 38.16 & 47.35 & * \\
\hline Hip ROM (') & 0.56 & 1.26 & 0.24 & 1.36 & 0.48 & 1.13 & 0.22 & 1.20 & \\
\hline Knee angle at footstrike ( $\left.{ }^{\circ}\right)$ & 25.05 & 5.45 & 21.59 & 28.52 & 24.67 & 9.12 & 18.88 & 30.47 & \\
\hline Peak knee flexion ( ${ }^{\circ}$ ) & 45.90 & 4.48 & 43.05 & 48.75 & 47.90 & 6.41 & 43.82 & 51.97 & \\
\hline Knee ROM ( $\left.{ }^{\circ}\right)$ & 20.85 & 7.38 & 16.16 & 25.54 & 23.22 & 8.54 & 17.80 & 28.65 & \\
\hline Ankle angle at footstrike $\left({ }^{\circ}\right)$ & 4.56 & 6.93 & 0.15 & 8.96 & 12.74 & 2.62 & 11.07 & 14.40 & * \\
\hline Peak dorsiflexion $\left({ }^{\circ}\right)$ & 18.35 & 4.17 & 15.70 & 21.00 & 22.82 & 3.85 & 20.37 & 25.26 & * \\
\hline Ankle ROM (') & 13.80 & 7.70 & 8.90 & 18.69 & 10.08 & 4.08 & 7.49 & 12.67 & * \\
\hline
\end{tabular}

Key: ${ }^{*}=$ significant difference 
Table 2: Peak hip, knee and ankle loading parameters (Mean, SD and 95\% CI's) as a function of footwear.

\begin{tabular}{|c|c|c|c|c|c|c|c|c|c|}
\hline & \multicolumn{4}{|c|}{ Barefoot } & \multicolumn{4}{|c|}{ Shod } & \\
\hline & Mean & $S D$ & 95\% Cl Lower & 95\% Cl Upper & Mean & $S D$ & 95\% Cl Lower & 95\% Cl Upper & \\
\hline Peak patellofemoral force (BW) & 4.32 & 0.93 & 3.73 & 4.91 & 4.51 & 1.07 & 3.83 & 5.19 & \\
\hline Peak patellofemoral stress (MPa) & 5.05 & 0.93 & 4.46 & 5.64 & 5.14 & 0.78 & 4.65 & 5.63 & \\
\hline Patellofemoral instantaneous load rate (BW/s) & 159.55 & 56.26 & 123.81 & 195.29 & 149.80 & 56.60 & 113.84 & 185.76 & \\
\hline Peak Achilles tendon force (BW) & 6.85 & 1.95 & 5.61 & 8.09 & 6.07 & 1.22 & 5.29 & 6.84 & 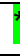 \\
\hline Achilles tendon instantaneous load rate (BW/s) & 174.17 & 85.71 & 119.71 & 228.63 & 142.16 & 32.01 & 121.83 & 162.50 & \\
\hline Peak medial tibiofemoral force (BW) & 6.53 & 1.64 & 5.49 & 7.57 & 6.23 & 1.25 & 5.44 & 7.03 & \\
\hline Peak medial tibiofemoral stress (MPa) & 12.51 & 2.75 & 10.76 & 14.26 & 11.77 & 2.04 & 10.47 & 13.07 & \\
\hline Medial tibiofemoral instantaneous load rate (BW/s) & 289.17 & 142.69 & 198.50 & 379.83 & 167.57 & 77.16 & 118.54 & 216.59 & 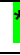 \\
\hline Peak lateral tibiofemoral force (BW) & 4.17 & 1.09 & 3.48 & 4.87 & 3.94 & 0.75 & 3.47 & 4.42 & \\
\hline Peak lateral tibiofemoral stress (MPa) & 13.15 & 3.56 & 10.89 & 15.41 & 12.32 & 2.17 & 10.94 & 13.70 & \\
\hline Lateral tibiofemoral instantaneous load rate (BW/s) & 179.59 & 60.90 & 140.89 & 218.28 & 116.40 & 30.13 & 97.25 & 135.54 & the \\
\hline Peak hip force (BW) & 9.70 & 1.32 & 8.86 & 10.53 & 8.51 & 0.94 & 7.92 & 9.11 & 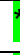 \\
\hline Hip instantaneous load rate (BW/s) & 377.38 & 140.49 & 288.12 & 466.64 & 167.25 & 78.35 & 117.47 & 217.03 & (1) \\
\hline
\end{tabular}

Key: ${ }^{*}=$ significant difference

Table 3: Step characteristics (Mean, SD and 95\% CI's) as a function of footwear.

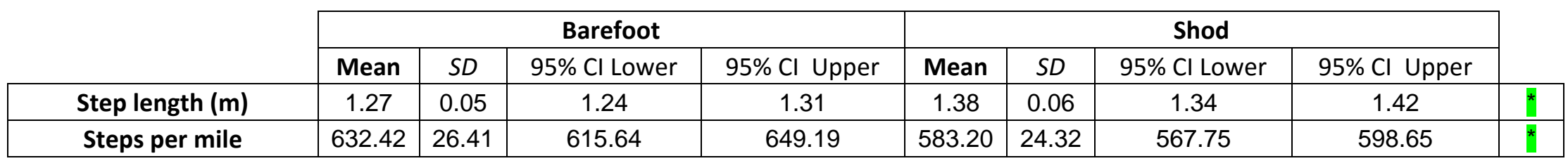

Key: ${ }^{*}=$ significant difference 
Table 4: Joint loading per mile (Mean, SD and 95\% CI's) of hip, knee and ankle loading.

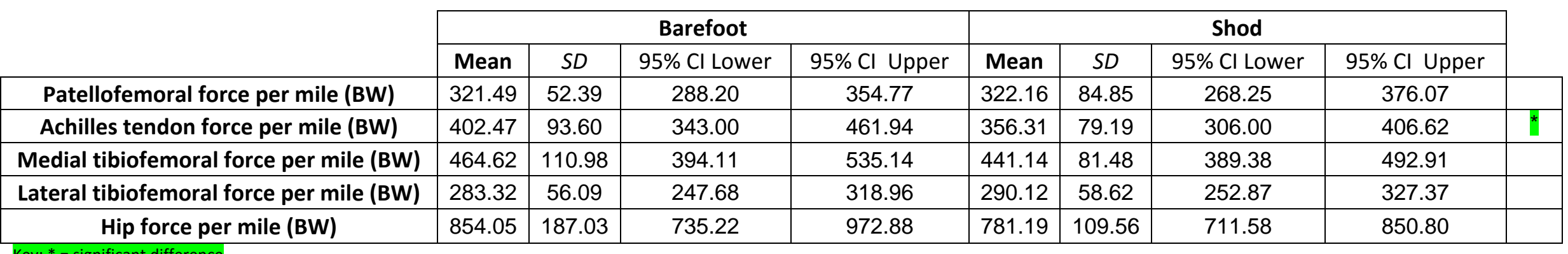

Key: ${ }^{*}=$ significant difference 